\title{
SURFACE SALINITY OF COCHIN BACKWATER WITH REFERENCE TO TIDE
}

\author{
By M. J. GEORGE AND K. N. KRISHNA KARTHA \\ Central Marine Fisheries Research Sub-Station, Ernakulam-d
}

\begin{abstract}
I N T R O D U C T I O N
IN connection with the prawn studies of the Sub-station, routine observations on the surface salinity, temperature, oxygen etc., were conducted regularly in the Cochin backwater for the past few years. A paper on the plankton and its relationship with salinity of the Bunder canal at Narakkal connected with the backwater has been published (George, 1958). For this study, observations along the canal were made throughout during the high water. A doubt then arose whether it would give a true picture of the conditions of the canal by following only the high waters of each day since varying amounts of sea water might enter into the backwater and from there into the canal during the high water, bringing with it planktonic organisms and salinity conditions which are more marine than what had existed during the low water. Balakrishnan (1957) while studying the surface salinity of Ernakulam channel noticed a number of rapid fluctuations which were attributed, to a certain extent, to the influence of tide. The present work is an attempt to understand the amount of tidal influence, if any, on the salinity of the backwater, at the various heights of the tide and to see whether two different conditions, one during high and the other during low water, exist in the area.
\end{abstract}

\section{MATERIAL AND METHODS}

Water samples for salinity estimation were collected once a week at a fixed station in Ernakulam channel (Fig. 1) near the C.M.F.R. Sub-station regularly at six in the morning. This station is a few hundred yards south of I. N. Jetty. Owing to certain difficulties it was not possible to make observations twice a day once during the low water and the other during the high water, which would perhaps have helped in a better understanding of the problem. However, it was possible to divide the entire data of any given month into two different sets, one falling in the time of low water and the other in that of high water. With the aid of the TideTable the duration of the tide at Cochin (from the minimum height to the maximum height of sea level, or vice versa, as the case may be) covering the sampling time was found out. This entire period was divided into two equal halves, one half beginning or ending with the minimum height and the other with the maximum. The sampling was then classified as from the low water or from the high water considering the half in which the sampling time fell. By this method it was found that out of a total of 94 observations, covering a period of two years (1957 and 1958), 52 observations were from the low water and the rest from the high water. Again, at least one observation from either set was present during any month. These results have been plotted for comparison. 
This method of treating the data has, however, a drawback in the present purpose as the actual sea-level at two different low waters (or high waters) may vary considerably. In fact, it was found that during some of the minimum tidal heights of certain days, the sea level was really higher than some of the maximum heights

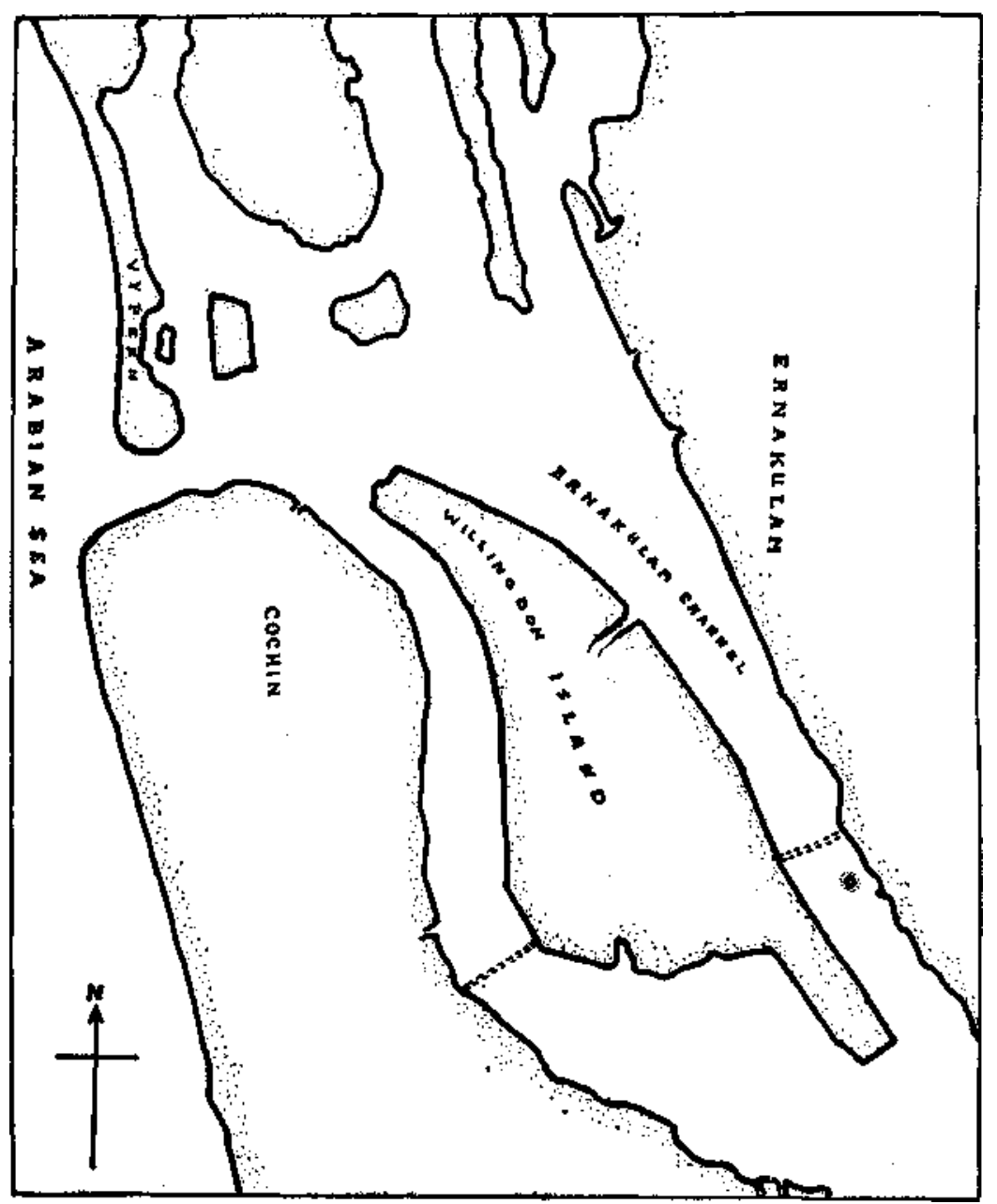

Fig. 1, Map showing Ernakulam channel and the connection of the backwater with the sea. The circle indicates the spot at which the observations were made.

of some other days. For example, it may be mentioned, that one of the minimum heights of water on 12-1-'57 was 2.8' while one of the maximum heights on 26-3-'57 was only $2.1^{\prime}$. The amount of sea water that would penetrate the backwater is, in general, proportionate to the height of the sea level and, therefore, the amount of sea water that should have been in the channel during the minimum height on 12-1-'57 must have been more than what would have been there during the maximum height on 26-3-'57 and hence the conclusion that would be arrived at, purely by separating the tide into the two phases would at times be misleading. Therefore, in order to have a more accurate idea, the exact height of the tide at the sampling time was 
calculated and the two factors, height of the tide and salinity were treated statistically. The height of the water at the given time was calculated from the tables given for the purpose at the end of the ' Tide-Tables of the Indian Ocean.'

\section{OBSERVATIONS}

It was noticed by Balakrishnan (1957) and George (1958) that, in the Ernakulam channel and the Narakkal Bunder Canal, respectively, in the Cochin backwater, the surface salinity varies from that of fresh to that of sea water. Such annual variation of salinity in estuaries is not surprising as they are controlled by sea on one side and the rainfall and run off on the other. Rao \& George (1960) observed similar variation in Korapuzha estuary in the south west coast of India.

In the Ernakulam channel, according to the trend of surface salinity studied of the five years, 1956-60, there appears roughly three seasons in any year. The first, a season of low salinity, starts somewhere in May with a sudden drop in the surface

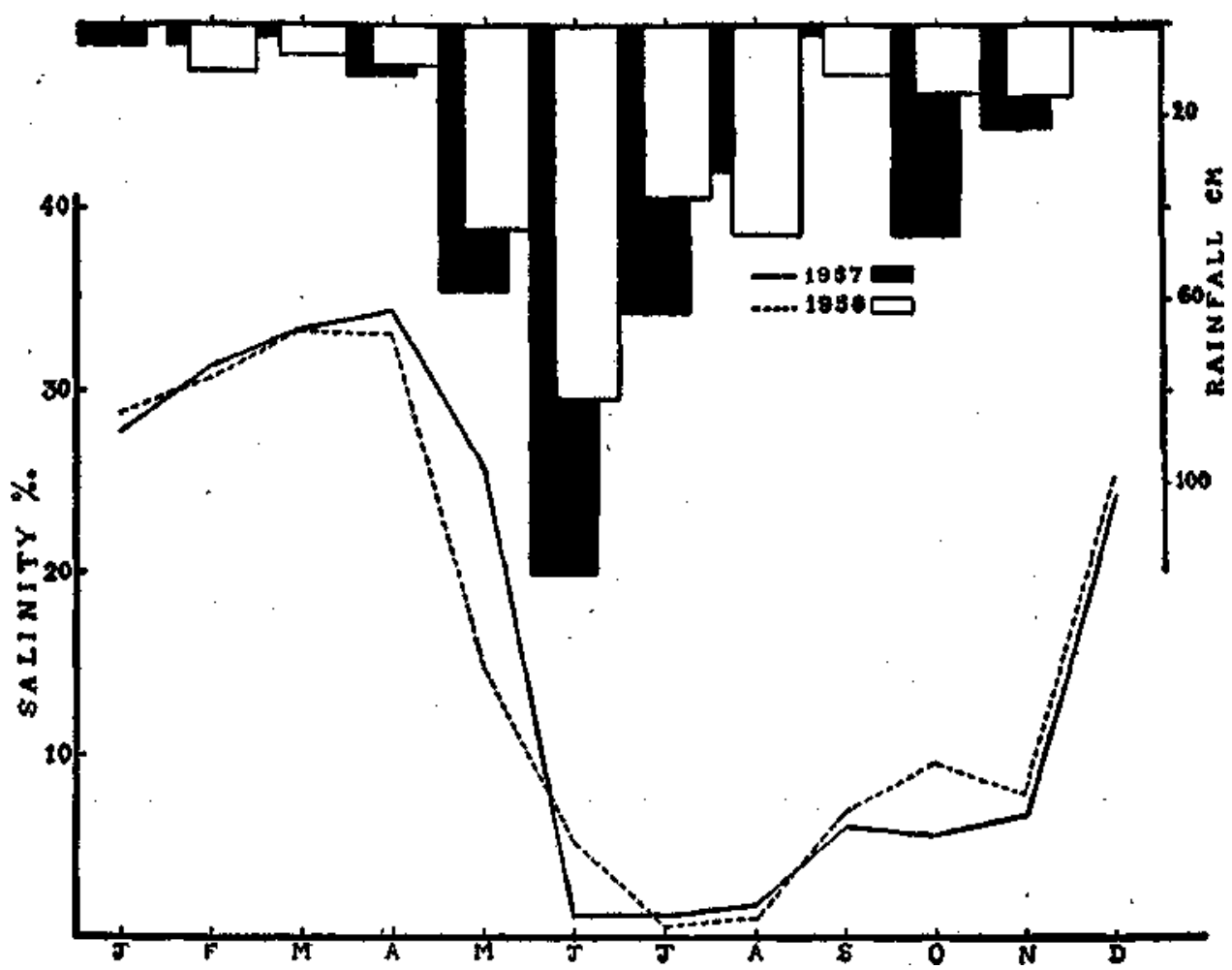

Fig. 2/ Showing the surface salinity and rainfall for the years 1957 and 1958.

salinity, associated closely with the commencement of the S.W. monsoon. This season extends somewhere up to September-October. The surface water of the channel throughout this period remains almost fresh, obviously resulted from the heavy rains and the continuous run off. Fig. 2 shows the correlation between the 
rainfall and the drop in the surface salinity. This season is followed by the postmonsoon season, that is September-October to December-January, when the surface salinity of the channel has, in general, an upward trend, probably due to the

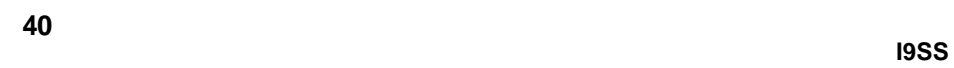

1356 , A

Z

$3^{\circ}$

w 40

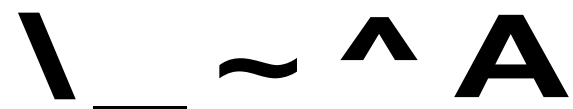

1

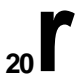

I

1939

20

0

40

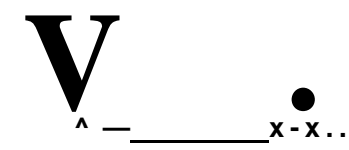

$/ \mathbf{v} / \mathbf{v}$

1960

20

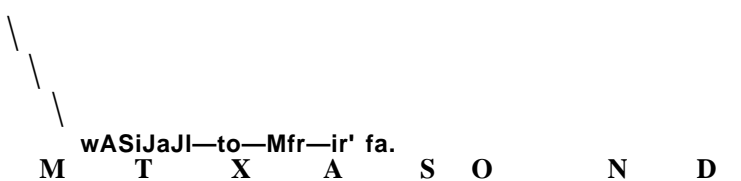

$\mathbf{F}$

Fig. 3. The weekly salinity values for the years $1956-60$.

progressive mixing from the sea enabled by the lesser run off and the increased evaporation. This period of salinity increase, unlike the low salinity period, is characterised by a number of rapid fluctuations in the weekly salinity values (Fig. 3). By January the salinity almost reaches its height and throughout this third season, January to May the channel contains water comparable in salinity to the inshore water.

The salinity curves for separate high and low water values (Fig. 4) show that the trend is same in both cases suggesting that direct tidal influence in the channel surface is practically nil during any part of the year. The regression line drawn of salinity with height of tide (Fig. 5) shows that the values are not interdependent $j$ correlation coefficient was equal to 0.05 and hence not significant. 


\section{DISCUSSION AND CONCLUSION}

Rao \& George (1960) stated that the salinity distribution in estuaries are controlled by tide. According to them ' observations at the river mouth have revealed considerable salinity fluctuations due to tidal influence' in the Korapuzha estuary.

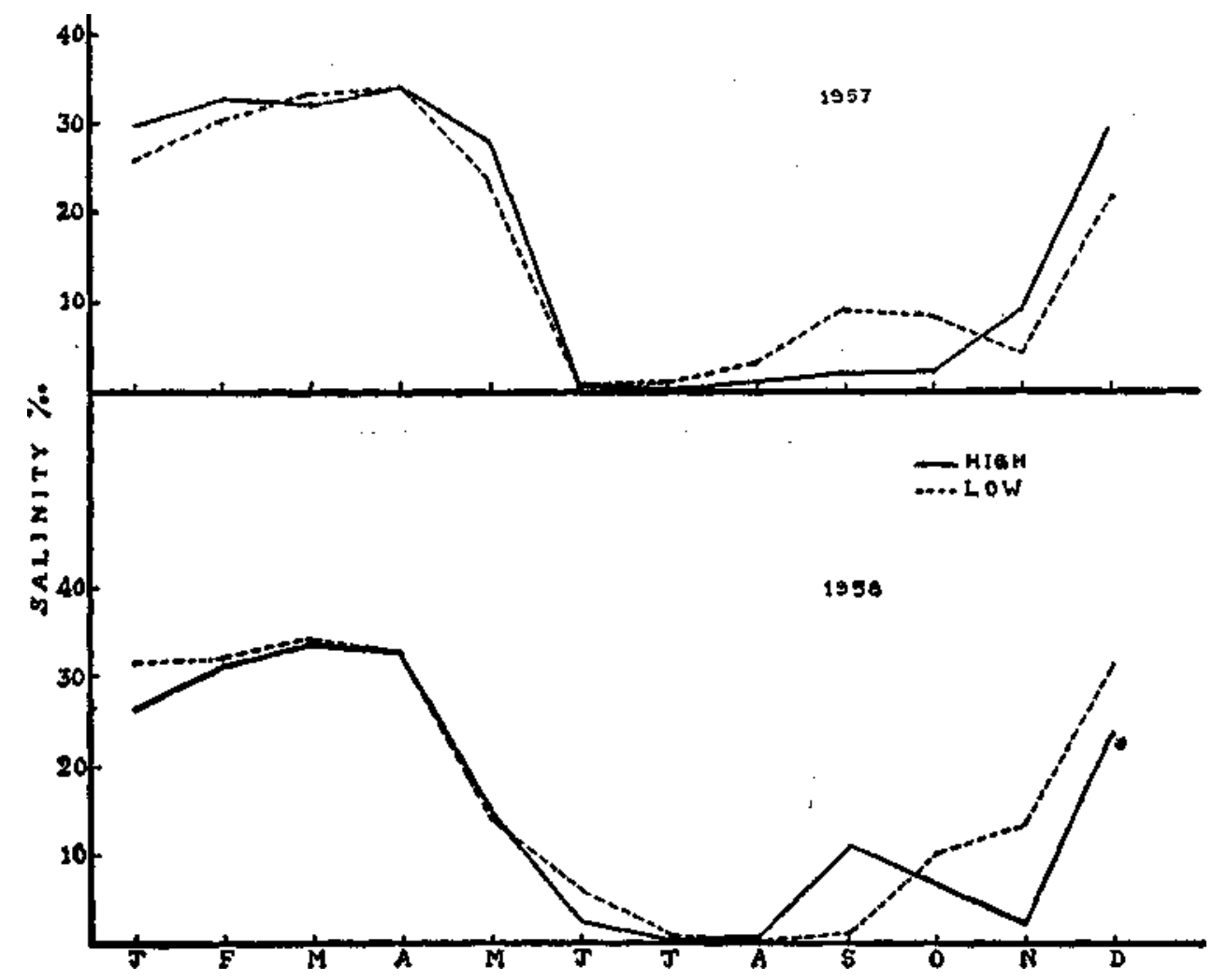

Fig. 4. The curves for separate low water and high water salinity values.

But, unfortunately, these have not been dealt with in detail. In theErnakulam channel, however, no such distinct influence was apparent along the surface, particularly during the low salinity period. During this period, as has been pointed out before, any such influence would have brought about a marked fluctuation in the salinity, as the salinity in the sea does not go below 21 to $22 \%_{0}$ (Jayaramanpersonal communication). So also it would have enabled consequently some of the typically marine forms like chaetognaths, Pleurobrachia etc. present in the sea off Cochin at that time to be present in the backwater. But George (1958) has not observed these forms during this period. The lack of tidal influence from the sea during this season may be due to the high water level in the channel and the low tidal amplitude off Cochin (which rarely exceeded 2.5' at the highest point). Balakrishnan (1957), however, has observed in 1955, a number of rapid fluctuations through various months which were attributed, to a certain extent, to the influence of tide. But from the figure provided these fluctuations are seen to be of significance only during JulyAugust. It is of interest to note that the rainfall in 1955 had two distinct peaks and during July-August it was in the decline. Similar fluctuations in salinity values are 
noticed also by the present authors between September-October to DecemberJanuary every year (Fig. 3). These fluctuations could not be directly attributed to the

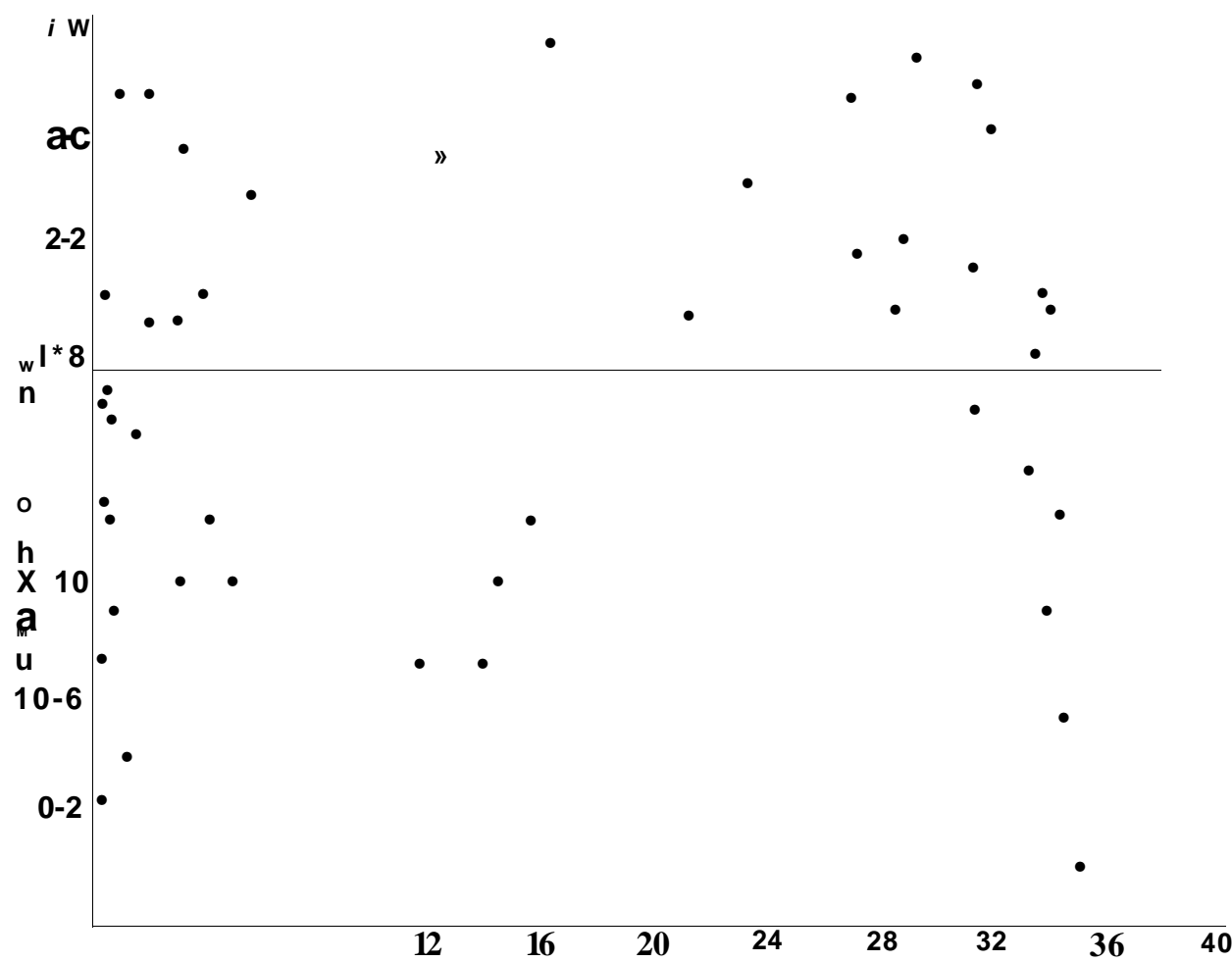

S A L I N I T Y \%.

Fig. 5. The regression line of salinity with height of tide.

tides. Had these fluctuations been effected by the tides, higher salinity values could be expected more regularly at all high waters which, however, was not the case. It is seen from the individual salinity values that high and low values were appearing quite independent of the tidal heights. Further, a few observations of salinity of the water at subsequent high and low waters of a single day during this period of fluctuation given in Table 1 shows it clearly.

TABLE 1

Showing salinity values of consecutive high and low waters of a single day

\begin{tabular}{c|c|c}
\hline Date & Salinity $\%$ at high water & Salinity $\%$ at low water \\
\hline $21-10-60$ & 5.63 & 7.97 \\
$26-10-60$ & 9.60 & 19.89 \\
$2-11-60$ & 1.66 & 1.47 \\
$9-11-60$ & 1.84 & 2.38 \\
$16-11-60$ & 0.21 & 0.39 \\
$23-11-60$ & 1.29 & 20.25 \\
$30-11-60$ & 1.66 & 1.47 \\
$7-12-60$ & 6.89 & 25.30 \\
\end{tabular}


In 1955, from the surface temperature data provided by Balakrishnan (pp. cit.), it is seen that the temperature in monsoon months though low compared to the other months, had an inverse relationship with salinity. Low temperature was almost always recorded with higher salinity values. It is reported (Banse, 1959) that in the S.W. coast the surface temperature during the monsoon months, up to the end of October-November, is very low. This low temperature, according to him, is due to upwelling. It should be borne in mind that Ernakulam channel at its deeper reigon is more than 10 metres deep and the study so far was confined only to the surface layers. It may not be, therefore, improbable that more saline and cooler water from the sea is present in the bottom region along the channel during the monsoon months which becomes evident along the surface only when the rainfall and the run riff are in the decline. During heavy rains and run off the upper layer gathers a distinct stratum of fresh water without allowing much mixing from below. A detailed study of the stratification of the backwater* which is being taken up in the Sub-station, may throw more, and perhaps a conclusive light on the problem.

After the post-monsoon season, the surface salinity of the channel reaches almost its maximum height. With the considerable reduction in the run off from the canals and rivers and with the increased evaporation, the water along the surface is replaced gradually by the sea water until at last by the end of January a tongue of seawater is present in the channel. This is indicated by the high salinity valuer and constant presence of marine planktonic organisms in the area (George 1958). During this period there is regular tidal flow because of the low water level of the channel. But, however, this is not perceptible either in the salinity readings or in the plankton, since the water already contained in the channel is the inshore water.

\section{SUMMARY}

The surface salinity of the backwater in Ernakulam channel has been studied for 5-years 1956 through 1960 and it is found that tidal influence on the salinity of the channel surface is practically nil. According to the trend of surface salinity there appears to be three seasons in any year, a season of low salinity from June to September-October, a post monsoon season with upward trend in salinity from September-October to December-January characterised by rapid fluctuations in salinity values, and January to May when the channel contains water comparable in salinity to the inshore water. The results indicate the probability of the presence of more saline and cooler water in the bottom region along the channel.

\section{ACKNOWLEDGEMENTS}

The authors wish to express their thanks to Sri R. Jayaraman for his valuable suggestions and criticisms.

\section{REFERENCES}

BALAKRISHNAN, A. 1957. Variation of salinity and temperature in Ernakulam channel. Bull. Cent. Res. Inst., University of Kerala, series C. 5 (2) : 7-9.

BANSE, K. 1959. On upwelling and bottom-trawling off the south west coast of India. Jour. Mar. biol. Ass. India, I (1): 33-49. GEORGE, M. J.. 1958. Observations on the plankton of the Cochin backwaters. Indian J. Fish.,

RAO, S. V. S. \& GEORGE, P. C. 1960. Hydrology of the Korapuzha estuary, Malabar, Kerala State. Jour. Mar. biol. Ass. India, 1 (2):212-223. 